\title{
Educational Milieu Formation: Social and Cultural Aspects
}

\author{
Eugenia V. Listvina \\ Department of Philosophy, Saratov State University, Saratov, Russia \\ Email: listvamer@yandex.ru
}

Received March 2014

\begin{abstract}
This paper presents the interrelationship between the concepts of educational milieu and educational area, characterized by systematic, internal integrity. The attempt is also undertaken to specify the relationship of the educational milieu with the determination of the culture role in the education itself. The author notes the fundamental role of cultural and mental components inscribed in the very structure of the educational milieu in the process of getting education. In the context of educational process elements unification educational milieu contributes to the preservation of the socio-cultural persistent forms developed on the basis of cultural traditions.
\end{abstract}

\section{Keywords}

Educational Milieu, Educational Area, Culture, Mentality

\section{Introduction}

In the modern context of education advancement the role of the concept of educational milieu is becoming more important. While education becomes deterritorialized, deinstitutionalized, when the process of education and information perception becomes vague enough and not linked to specific topos, the subject of the milieu itself generates the interest. Specifically, the educational process requires clearly stated localization if not territorial then symbolical any way. And phenomenon of milieu meets these requirements.

\section{Social and Cultural Aspects}

\subsection{Concepts of Educational Milieu and Educational Area}

One ought to distinguish between concepts of educational milieu and educational area. Educational area is often thought of as "a result of potential integration of the present educational system components; in terms of one of the levels of the social space (together with economic, political and cultural space); as a phenomenon in social relations of the countries; as specific quality of unity; as a result of constructive activities [1].” The characteristics of the educational milieu include affection on all the senses and organs of the learner, availability of the main and peripheral information, symbolical and psychological meaning, adaptive and socializing functions, the influence as a unit [2]. 


\subsection{Educational Milieu and Culture Role}

In recent times aiming for demolition of boundaries and technical capabilities shows the aiming for development of the total educational area without conventions and fixing to the state and other systems. It appears that the more open a learner is in the course of knowledge gathering, the more productive the result will be. There is provided the existence of so called total educational milieu which is not parted by any boundaries and that fully associated with the educational area, for example in medieval Europe, enabling the students moving regardless of political boundaries. However, the experiments of the latest decades are the reflection of the fact that these wide opportunities lead to some surprising conclusions.

Involving into the different education systems, even into the most universal Bologna system as a united European Higher Education area, an individual one way or another has to be in contact with communicative, discursive, cultural practices accompanying education process, elements of the everyday culture, acting as a two-sided filter both on the part of a learner and on the host side.

Thus, the educational milieu is closely linked to the determination of the culture role in the education itself. If we turn to the definitions of the culture, the definition of V.S. Stepin which specifies the culture as a system of historically connected, developing suprabiological programs providing reproduction and change of social life in all its basic aspects will be the most responding to our research [3]. Following in V.S. Stepin's tracks we can say that culture creates its own special "container" for what we call socialization, and even enculturation to a greater extent. According to I.T. Kasavin, almost everything that a person gains as knowledge like a form of social and individual memory, a convoluted performance and communication scheme, a result of indication, structuring and interpretation of objects in the learning process for all its universality "is colored" into specific cultural, mental shades.

By all means knowledge and information gathering is carried out through the prism of the culture concept, i.e. education perception as "a cultural process exercised in the culture forming educational milieu where all the components are filled with human sense, work for a person who freely shows his/her individuality and is good at cultural self-development and self-determination in the world of cultural values" is formed [4]. We would also add the mental components featuring the deep level of consciousness, including the unconscious, undifferentiated steady set of attitudes and aptitudes of an individual or a social group to perceive the world and themselves in this world in a certain way. According to the well-known characteristics mentality is formed depending on traditions of culture, social structures and the whole sphere of human life and activities, at the same time actively influencing their formation. But in this case it is more important to emphasize its syncretism, perplexity of rational and irrational factors which break a new ground for any informative, educational activity perception.

And then a specific cultural, mental component which is found to be very naturally inscribed into the very structure of the educational area and of the educational milieu altogether starts to play an important, foundational role in the process of getting education.

It is the syncretism, internal integrity of the educational milieu that should be made a point of. Educational milieu appears to be integral syncretical phenomenon wherein a learner is fully intented, without any conditionalities. It is a complete state of effective output, solution in the process when the process is not divided into separate operations, lessons, lectures, classes in the learner's mind but is perceived as some natural continuum. The educational milieu absorbs the learner since he/she enters the educational system even if it is not a specific institution, premises, complex with its particular territorial and spatial characteristics. This happens to be one of the foundational elements of knowledge acquisition extent because no matter how we try to rely only on the rational principle in knowledge gathering, its assimilation goes through mental schemes. And here the educational milieu takes center stage as it emphasizes specificity of presentation and structuring of materials, learner psychological state formation.

\subsection{Educational Milieu and Collective Memory}

The elements of collective memory which promote a special collective ground unifying students groups and including intergenerational traditions play the considerable role in formation of educational milieu based on unity of education and life. According to Moris Halbwachs, "in addition to the recorded history there is a real history [5]", which is exactly fixed with the collective memory holding the community together highly firm and originally. Besides the collective memory of the nation which is generally in the foundation of the educational milieu each educational institution, each students group daily create specific space of the collective memory fixing 
considerably stronger than just prescribed regulations and statutes. In this context educational milieu in some degree appears to be a generator increasing collective memory, animating and inculturing its key facts and events. Educational milieu is shot through with collective memory, its specific, most dramatic events which in course of time become central and enable to unite the learners in the course of educational process besides assimilation of education program itself.

Collective memory facilitates more comfortable immersion into the absolute space of the educational milieu, helping to pass the intergenerational traditions. In fact, collective memory helps modeling of educational milieu, highlighting the necessary key points and developing edgy pathways, which the learners will be getting along, gaining the specific knowledge and simultaneously with this perceiving the mental foundations of culture within which the educational process is carried out [6].

Consequently, one might say that by formation of the educational milieu through the collective memory it is possible to solve the problem of the identity crisis of the younger generation in some ways which now involves different levels and layers of the social structure and creates conditions of sociocultural tension. According to V.S. Stepin, "social and cultural after-effect of the identity crisis is the tendency for diffusion of the intersubjective semantic structure, postmodern playing with meanings of the cultural universals. Cultural community with indistinct social structure gravitates toward strategies of deconstruction and bricolage, socially irresponsive playing with cultural meanings [7].” If this occurs the educational milieu turns out to be opposing source to this indistinct tendencies, the element which fixes and "cements" a personality that becomes able to survive under the complex, ever-changing conditions of the modern age.

\section{Conclusions}

Principle of organization of the modern educational process is defined as unity of education, life and professional activities. It is educational milieu that creates this steady and, if the expression may be tolerated, comfortable unity. It consists of all the culture elements which prepare educational process from inter-generational communication of the process participants to selecting samples for testing. Even if a learner does not work towards this and wishes to be outside mental schemes, after all he/she has to absorb them in order to get the desired result of the educational process.

Consequently, we can conclude that no matter how we come in contact with formalization and unification of individual stages and elements of educational process, educational milieu naturally continues and strengthens social and cultural stable forms fully developed on the basis of cultural traditions and mental ideas. In this it will be seen one of the resources of modern education which enriches the process of knowledge gathering and makes its fullest and complete acquirement and practice possible.

\section{References}

[1] Leonova, O.A. (2008) The Concept “Educational Area” and Its Regional Interpretation. Pedagogika, 6, 37.

[2] Bekker, I.L. and Zhuravchik, V.N. (2009) The Educational Area as a Social and Pedagogical Category. Proceedings of the Penza State Pedagogical University Social Sciences, 12, 136-138.

[3] Stepin, V.S. (2011) Civilization and Culture. SPGUP, St. Petersburg.

[4] Bondarevskaya, E.V. (2000) Theory and Practice Person-Oriented Education. Rostov-on-Don.

[5] Halbwachs, M. (2005) Collective and Historical Memory. Emergency Reserves, 2-3, 40-41. http://magazines.russ.ru/nz/2005/2/ha2.html

[6] Podzorova, S.V. (2011) The Educational Milieu Is the Important Notion of Reality. Newsletter of the Classical Scientific Education, 1, 41-47.

[7] Pirozhkov, V.V. (2014) Discussion of the Academy Fellow Stepin V.V. Book "Civilization and Culture” (the Materials of the Roundtable Discussion). Philosophy Issues, 1.

http://vphil.ru/index.php?option=com_content\&task=view\&id=877\&Itemid=52 